\title{
Tangerine Tomato Juice
}

National Cancer Institute

\section{Source}

National Cancer Institute. Tangerine Tomato Juice. NCI Thesaurus. Code C116327.

Tomato juice derived from the tangerine tomato, with potential antioxidant and chemopreventive activities. Tang erine tomato juice contains higher levels of the cisisomer of lycopene (cis-LYC) compared to the trans-isomer (trans-LYC). Lycopene, a linear, unsaturated hydrocarbon carotenoid, is the major red pigment in certain fruits such as tomatoes, pink grapefruit, apricots, red oranges, watermelon, rosehips, and guava. As an antioxidant, lycopene scaveng es free radicals, which may both inhibit cellular oxidation and prevent free radical damage to cells. cis-LYC is better absorbed than its trans form. 